\title{
Health Professionals' Perceptions on the Integration of Medical Students' Training in Family Health Care Units
}

\author{
Percepção dos Profissionais de Saúde em \\ relação à Integração do Ensino de Estudantes \\ de Medicina nas Unidades de Saúde da \\ Família
}

Fabiana Arenas Stringari de Parma ${ }^{I \odot}$ Raquel Aparecida OliveiraII Fernando Antônio Almeida

\section{PALAVRAS-CHAVE \\ - Educação em saúde. \\ - Ensino. \\ - Integração à comunidade. \\ - Integração docente assistencial. \\ - Atenção primária à saúde.}

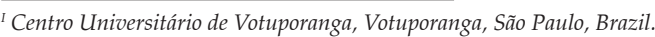

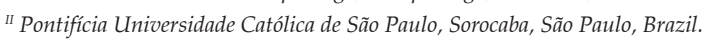




\section{KEY-WORDS}

- Health Education.

- Teaching.

- Community Integration.

- Healthcare-Teaching Integration.

- Primary Healthcare.

\begin{abstract}
Introduction: The Centro Universitário de Votuporanga (UNIFEV) medicine course was implemented in 2012 according to the 2001 National Curricular Guidelines for Undergraduate Medical Courses. The practical module of Community Service Education Integration is the curricular unit that places students into Primary Health Care (PHC) scenarios from the first period of the course until the internship period, breaking with the traditional model of hospital-centered training, which is segmented into specialties. The module of medical skills and attitudes training also leads the student, in some cases, to PHC services, but with focus on the basic clinical procedures in controlled scenarios, which may be those from typical clinical practice, simulations or even those performed in laboratories. During internship, the student continues in PHC as an intern in general, family and community medicine. In this context, the integration of community-education-service plays a major role in the transformations undergone in undergraduate training in health, which are also aimed at modifying the current healthcare model. Objectives: To understand the perception of professionals from the Family Health Care Units regarding medical student work placement and to interpret the results of this integration as far as the service, the community and the medical training are concerned. Methodology: Qualitative research carried out with health professionals who work in three Family Health Care Units of Votuporanga, São Paulo, Brazil. They were invited to participate in focus groups to express their opinions about thought-provoking questions. The recorded material was transcribed, organized and analyzed according to Bardin's content analysis, which allowed categories of analysis to emerge based on what the participants said. Results and discussion: The opinions that have emerged allow to identify the following aspects: teaching-service-community integration contributes to medical education; student presence promotes team integration and self-learning and promotes the work process; student integration has impact on the community. Among the student's contributions, participants highlighted the academic and health care reflective practices, health education actions and complementary activities that support the health team in solving local problems. Participants also identified some situations of difficulty, such as: students in the early periods of the course need to acquire affective domains for an adequate professional posture at PHC units; the embarrassment of patients in the medical consultation with the presence of students; and the short length of stay of the students for the necessary bond building. Conclusion: For PHC professionals, the inclusion of students in these scenarios contributes to the development of the service, medical training and community support. Due to the solidary relations existing between the educational institution and the PHC management, this research may contribute to promote the necessary adaptations and prepare the community and professionals for the presence of students in PHC.
\end{abstract}

\section{INTRODUCTION}

The Medicine Course of Centro Universitário de Votuporanga-SP (UNIFEV) was introduced in 2012, in line with the National Curricular Guidelines (NCG) [Diretrizes Curriculares Nacionais - DCN)] for Undergraduate Courses in Medicine (CNE/CES [National Council of Education/Council for Higher Education] Resolution no. 4, of $11 / 7 / 2001)^{1}$, which stipulate the skills and abilities needed in the training of generalist doctors and indicate that the essential contents are related to the determining factors of the health-sickness process, integrated with the epidemiological and professional realities, and places its students in primary health care (PHC) settings right from the first period of the course.

In 2014, an update to these NCG (CNE/CNES Resolution no. 3 of 20th June 2014) $)^{2}$ stipulated the compulsory internship to be carried out in the Brazilian Unified Health System - the Sistema Único de Saúde, or SUS, in the primary health care (PHC) and emergency services settings. 
The teaching plan of the medical course at UNIFEV is based on active teaching-learning methods, and gives preference to educational activities in primary health care, as well as secondary health care and complementary units. The curricular matrix has a total of 7708 hours; 4248 in theoretical/practical curricular units, 100 hours of complementary activities, and 3360 hours of compulsory internship. The course contents were grouped and distributed in curricular units that promote the development of skills related to health care, health care management and health education ${ }^{3}$. Each semester is called a "period", and corresponds to one thematic unit, according to the following stages in the life cycle: 1st period - adolescence; 2nd period - conception and pregnancy; 3rd period - newborn and childhood; 4 th period - adult woman; 5 th period adult man; 6th period - aging and death; 7 th period - integral health care I; 8th period - integral health care II; 9th, 10th, 11th and 12th periods - compulsory curricular practical training placement or internship.

The periods are comprised of the following curricular units (keeping the Portuguese acronyms): Laboratory Practices (PL), Tutorial Module (MT), Skills Training and Medical Attitudes (THAM), Practice of Integration between Teaching and Community Service (PIESC) and Integrated Case Study (ECI).

Thus, PIESC is the curricular unit that has the didactic, pedagogical and social accountability to provide the student with experience in the practical PHC setting, from the first period of the course.

The first cycle of PIESC occurs in the first three teaching periods. In the first period, groups of ten students, accompanied by a tutor, identify the health needs of adults and children across different sectors (social welfare and education) of a Primary Health Care Unit (PHCU), such as the Social Welfare Reference Centre [Referência de Assistência Social-CRAS)], and elementary schools. In the second period, the students produce an intervention project in children's health, focusing on the health need investigated in the previous semester. This project is produced with full scientific rigor, such that the student understands all the steps in a research study, and it must be submitted for approval by the Research Ethics Committee of the institution. In the third period, this project is developed and evaluated. In the second cycle of PIESC - which runs in the fourth, fifth and sixth periods of the course - the students identify collective health needs and develop an intervention project for a specific population group, correlating it with the life cycle of the teaching period that is in progress at the time. In the final cycle, which takes place in the seventh and eighth periods, the students gain practical experience of aspects related to health care management and surveillance, and reflect on them in Family Health Units (FHU), PHCU, Psychosocial Care Centres (CAPS), Specialized Care Services (SAE - STD, AIDS and Hepatitis) and the Municipal Department of Health.

In the curricular unit THAM, the students also takes part, along with their medical tutors from UNIFEV, in controlled scenarios, simulations, or clinical practice in an FHCU, to gain training in the specific basic clinical procedures taught in each period.

When it is time for the internship, the student carries out a two-year practical training placement, with a total of 672 hours, working in General, Family and Community Medicine (MGFC) under the direct supervision of a preceptor, which is the doctor of the Family Health Team (FHT). This is the stage with the highest number of course hours.

Thus, UNIFEV placed students in FHUs, with their tutors, in the second semester of 2012 through to the second semester of 2016, when they began the internship and the family doctors of the services acted as their preceptors.

Pinheiro and Freitas ${ }^{4}$ report that some medical schools in Brazil are already grounded in a generalist training and the universalist healthcare model, with a commitment to the pursuit of social equality, because medical education and the development of research should keep abreast of changes in society, and be able to meet its needs.

However, in many medical schools, the focus is still on the Flexnerian (traditional) teaching model, which is hospital-centric and is geared towards diseases and medical specializations, making it difficult to see the person in a holistic way and hindering resolution of care in the PHC. This training is reproduced in the health services where the students work, and should be overcome by continuing education.

In this context, there has been much debate on the integration between teaching and service, in line with the sweeping changes that have been taking place in undergraduate courses in health, which aim to promote professional practices and changes to the current health care model ${ }^{5}$, justifying this research.

It is assumed that the placement of medical students in the FHU, besides developing and improving generalist medical skills and attitudes, can contribute to the continuing education of professionals and improve the quality of health care for the population of that territory. This is because the academic content and practices of the health services should be based on the concrete reality of the health needs of a specific population.

This research is intended to gather information about the perceptions of health professionals regarding the presence of medical students in the FHCU, and to identify the benefits and difficulties for the service, for the community, and for the medical training. Based on the perspectives of the health professionals, it will be possible to contribute to any necessary changes. 


\section{METHODS}

We chose a qualitative approach, which is able to incorporate the intentionality inherent to the acts, relations and social structures, focusing on aspects of a reality that cannot be quantified, and working with a multiple universe of meanings, feelings and values ${ }^{6}$.

The research was authorized by the Municipal Department of Health of Votuporanga, and approved by the Research Ethics Committee of UNIFEV, under Opinion no. 2154472/2017. There were no conflicts of interest.

The research participants were thirty-five health professionals (doctors, nurses, technicians and nursing assistants, dentists, oral health assistants, pharmaceutical, health agents, administrative manager and receptionist) from six Family Health Care Team (FHCT) in Votuporanga in 2016. The selection criteria included only professionals with more than six months of work experience, as we believe that is the time required for the professional to have knowledge and interaction with medical students in service.

Three FHCU were selected, with three FHCT each. These units were chosen based on their suitability as practical scenarios for the PIESC, from the first period of the course of medicine and for the internship, beginning in July 2016. In the two focus groups conducted in two of these FHCU, the data were similar, showing saturation. We therefore chose to perform another focal group only with generalist doctors of these FHCU, preceptors of the internship, who worked with the students full time, in their professional activities, providing teaching and assistance. This homogeneous group, consisting of eight doctors, created a protected environment that was conducive to the discussion of situations that arose during the preceptorship and health care, and with which all the participants could relate.

In the two heterogeneous groups, the synchronism was more difficult, and the mediator had the role of creating an environment conducive to discussion. But these groups, which were well exploited, generated more expansive reports and discussions, with a great wealth of information.

In the focus groups, the following trigger questions were used: (a) Have you noticed any difference in your work routines due to the presence of medical students?; (b) Have you noticed any differences in your behaviour and in that of other health professionals as a result of the presence of students? In your view, what are the benefits and difficulties for the service?; (c) What do you think the training of medical students should consist of? Where they should be trained?; (d) How do you think you can contribute to the training of medical students?; (e) Do you think that the population is benefited by the presence of medical students?; What are those benefits? Are there any disadvantages? If so, what are they?

After collection, the data were organized according to the steps proposed by Bardin's ${ }^{7}$ method of content analysis: pre-analysis, encoding the material, categorization of the results, inference and interpretation. The data were then grouped into the categories of analysis, and for the presentation of the data, excerpts from the health professionals' reports were used, identifying the participants using acronyms, according to their professional training and registration number, namely: $\mathrm{D} /$ doctor, $\mathrm{P} /$ pharmacist, HA/health agent, N/nurse, NT/nursing technician, NA/nursing assistant, OA/Oral health assistant, $\mathrm{DT} /$ dentist, $\mathrm{R} /$ receptionist, $\mathrm{M}$ /administrative manager.

\section{RESULTS AND DISCUSSION}

Based on the analysis of the participants' reports, four categories of perceptions emerged, which will be used as the subheadings for this section.

\section{The student promotes integration and self-learning in the} health team

One of the changes cited by the participants related to the behaviour of the medical professionals in their role as preceptor. This dual role of doctor and preceptor requires the professional reflect on, and explain actions that are normally performed automatically; but he/she may not always have the knowledge to do this, and has to study more:

\section{D3: [...] we have to reflect and explain.}

D3: [...] we have to explain actions that we did automatically... we have to explain to them why we arrived at this conclusion, or that diagnosis [...]

D7: [...] we end up having to study a little, in order to be able to respond.

The presence of the student forces the professional to engage in reflective practice, inviting them to reflect critically on their own knowledge and doubts. These actions diminish spontaneity and prompt analytical reasoning and continual training ${ }^{8}$. Therefore, the presence of the student motivates the medical professional to study, when they lack the knowledge needed to answer the students' questions. This, in turn, contributes to their self-learning and improves the quality of the work.

Other comments related to the exchange of knowledge and practices among the professionals of the team, particularly between the doctor and the health workers. The student 
appears to act as a communication link between these different professionals, which motivates the doctor to interact more with the team, and value the knowledge of the other members, in order to be able to meet the health needs identified, and respond to the student's questions.

As a result of the students' presence, the doctor is required to engage in interprofessional, interdisciplinary work more frequently, exchanging knowledge among the different professionals of the team and the health care network, in order to qualify the care that the student experiences.

One doctor made the following observation:

D14: With the student, the systematization of (interprofessional) health care set out in the Ministry guidelines [...] became much more frequent, integrating the multiprofessional care and performing the risk classifications, and they (the students) have to interact with the team and be interested in the patient's life [...] we teach them to give the patient attention, addressing not only the disease, but social question too.

Effective team work needs to be interdisciplinary, as no single professional holds all the knowledge to meet the health needs. However, integrated actions among professionals from different areas, around a common goal, are only made possible through continuous dialogue, to overcome the fragmentation of health care ${ }^{9}$.

In the statements below, we see that the student's integration into the team led to a continuous education among the professionals, through the exchange of information in the day-to-day work processes:

HA7: they contribute something that we're not sure about [...] they give guidance

HA7: if we have a question, we clear it up with the intern [...] it's another way of learning on the job

D14: medicine has many discoveries, and the student also brings new knowledge to the preceptor him/herself [...] the patient will benefit.

According to Ceccim and Feuerwerker ${ }^{10}$, continuing education is the production of knowledge in the day-to-day work of health institutions, based on the reality experienced by the actors involved, taking the problems faced in the day-to-day work, and the experiences of these actors, as the basis of the questions and changes.
In the internship, the preceptor is the team doctor, trained by the higher education institution. In return, he/she provides the SUS with this continuing education activity, contributing to the qualification of the healthcare network.

Despite the benefits presented, the interviewees also pointed out some negative experiences with the arrival of the students. Some of them had shown attitudes of disrespect towards the team and the patients, which were overcome during the integration, as noted below:

$\mathrm{N} 2:[\ldots]$ at the beginning they just laughed, they were impolite [...] this was a disadvantage for the unit and for the patients.

N11: in the clinic it's one thing, outside they're arrogant [...] it's about the person [...] the personality.

D3: he's very cocky, he wants to boss the team around [...] we were starting to get problems with two students; they only wanted to look after the patient [...] they didn't want to form bonds with the team [...] that idea of sickness and treatment [...] we gave them guidance and they started to adapt better.

We realized, from the participants' reports, that the students arrive at the service with incomplete affective development, as is normal when it comes to the cognitive areas. But their behaviour, attitudes, responsibility, respect, emotion and values changed quickly when the students were integrated into the reality of the service. Also, based on Bloom's Taxonomy, we see that the interaction between reflection, and working in real-life conditions, leads the student to improve in this area, as one of the categories of the educational process ${ }^{11}$.

The students may also be influenced by professionals that reproduce the hierarchical, individualistic model, perpetuating a lack of integration with the team. However, in order to overcome the barriers historically imposed on health training, medical students must have contact, early on, with the reality of the SUS. Teaching in service sharpens the students' critical and reflective skills when faced with a problem situation, and helps them to act in ways that will produce good results ${ }^{12}$.

\section{The student's integration has an impact on the Community} The participants commented on the patient's initial embarrassment due to the presence of another person besides the doctor, during the consultation. The team took note of the patients complaints, and used their knowledge to explain to the patient why it was necessary to have students in PHC. They also discussed the importance of better preparing the patients for the students' presence. The work of the team, providing information for the 
population, supported the integration of the student with the community and helped mitigate the initial complaints. It was identified that there was less embarrassment when the consultation involved just one student, together with the doctor.

D2: [...] there are some patients who don't feel comfortable when talking about a complaint, particularly if it's a woman with a gynaecological problem, and the student is a man [...] others miss them when the students are away on holiday.

HA1: Most of them (patients) are embarrassed by the number of people inside the room... two students and the doctor. They feel uncomfortable and end up not saying all they wanted to say, and then afterwards, on our visits, they tell us something that they hadn't said during the consultation.

HA5: We inform them, we tell them that the person is there, but they are under the doctor's guidance.

HA10: All change, at the beginning, seems strange, I noticed this in my area, at the start, people found it really strange, but acceptance came over time, and now, it has practically no influence on my work routine [...] there aren't many complaints [...] my area is quiet, it's well accepted.

D14: Some patients came and said: "Ah, it won't be the doctor who sees me, so I don't want it " [...] I gave them information, and we ended the consultation together [...] these are people I trust [...] they returned for the next visits [...] they felt more confident [...] they were integrating these new students as though they were part of our team.

For Oliveira et al. ${ }^{13}$, the meeting between professionals and users, and also between students and teachers, is linked to a new form of standardization in search of a new way of doing things, permeated by the work dynamics and organization, by the epidemiological panorama, and by the beliefs of those involved in the healthcare.

In the perceptions of health workers interviewed by Trajman et al. ${ }^{14}$, user's embarrassment was a negative aspect of the placement of students in the service. Users felt particularly insecure when embarrassing procedures and physical examinations were involved, as exemplified in our focal group with the gynaecological examination.

We therefore conclude that the doctor-patient relationship is based on the confidence that the doctor inspires, and on the patient's understanding of the doctor's reality, which should be presented by the doctor, in order to build a relationship of connection and empathy. Achieving this requires listening sensitively, with attention and interest. This is corroborated by the statements below:

DT12: There was a lack of instruction for the patient, they didn't explain what the students were doing there with the doctor.

HA6: Many who complain that they don't feel confident because they weren't warned.

Although they discussed the fact that the patient received more attention due to the students' presence, the participants also mentioned that the turnover of these students can make it difficult for them to form bonds with the patients. This is seen in the following examples:

HA1: The thing that makes it difficult to form a bond between the patients and the students is that they don't stay long, there's a high turnover [...] if they stayed for longer... this would make it easier to form a bond of trust between them.

D14: The patients now relate well to those who came and stayed longer [...] the patient is more at ease and even asks the doctor. [...] There has already been an improvement in this turnover.

This turnover is due to the need for the teaching to propose fields of various practical placements for the sixty students of each class of the medicine course. However, efforts should be made to minimize it wherever possible.

\section{The student contributes to the work process}

The integration of the students with the team, and with the community, has helped to strengthen some of the PHC activities, because when the teaching-learning process is based on the integration of students in the health service, this can lead to new forms of work organization, improving the qualifications of care 5 .

The Health Education groups, for example, began to take place more often and with greater adherence by the population.

D7: [...] students gave lectures, and the adherence of the population was immense [...] when the lectures were stopped, the population complained because they had learned a lot from the students, it was a very enjoyable integration.

AO3: [...] The guidance that they gave in the groups has been a benefit for the population. 
Student acting under the new curricular guidelines seem to be more sensitive to the model of education through dialogue, distancing themselves from verticalized educational practices that dictate behaviours to be followed. Thus, the student accepts that the user holds diverse technical-scientific knowledge that is no less legitimate, and this provides greater adhesion by the community to the health education groups developed in $\mathrm{PHC}^{15}$.

Besides contributing to the health education groups, discussions in the focus groups show that students, when they become part of the team, help out in different, multiprofessional tasks, sometimes even compensating for a shortfall in professionals of the PHC:

D5: the team had to organize the prescriptions of patients who used psychotropic drugs, and they helped the pharmacist a lot.

D14: when the lack of professionals in the technical nursing team generates some difficulty, they can go there and resolve the issue for the time being.

In the health services, the teaching activities are complementary and should contribute to resolving the problems presented by the reality. However, the student should not only serve as additional labour for the service, but should also be able to reflect on their professional training in the light of the health system, because a lack of critical reflection about the work processes established would only perpetuate a production-focused health care, when in fact, a change in these practices is needed ${ }^{16}$.

Another change that occurred in the work process related to the medical consultation. Initially, the consultations took longer when the students were present. The doctor, now also the preceptor, reports that the student performs the sequence of the medical consultation, then this sequence is repeated by the doctor. Sometimes the patient's complaint is reinterpreted in the professional's anamnesis, since, in order to develop this medical practice, the student needs to develop skills in the doctor-patient relationship that will depend on practice and knowledge. The doctor also checks the physical examination and explains the positive findings, as well as discussing diagnostic hypotheses and the required complementary tests, and reporting the recommended treatment:

D3: I thought that [...] with the students, the consultation time was longer [...] they examine, and we have to re-examine [...] there's the discussion [...] we have to reflect to explain why we have reached a certain diagnosis.
D1: the medical consultation time was longer (in the presence of the students), since with practice, we are able to understand more quickly.

In fact, the study of Trajman et al. ${ }^{14}$ showed that health professionals lack the time to give sufficient attention to students, and an international study reported that teaching in the outpatient setting decreases the preceptor's quantitative productivity ${ }^{17}$.

In the focus groups, the participants reported that the consultation time was longer when the students were present, but that this tended to balance out as the students gained more practice, without diminishing the quality. In addition, in the perception of professionals interviewed, longer medical consultations, with the students listening to the patient as well as the doctor, were seen as positive because the patient was listened to with greater attention, and expressed satisfaction with this:

D1: [...] it changed my routine, because the time spent on the consultation was greater with the student present.

D5: [...] this was resolved as the students gained more practice [...] or [...] it ended up with the same amount of time being spent on the consultation as we would spend ourselves.

N4: the student's attention is focused on the patient. He listens more, and often the patient needs this.

D6: [...] the patient ends up gaining more attention, and the student also has more patience to talk [...] and many like it.

NT4: they help in the consultations, with prescriptions, it's made things more efficient [...] while one is taking the patient's blood pressure, the other will be looking at something else, and it's helped the doctor deal with the flow [of patients] in the Unit, which is very great [...] they assist in the procedures [...] they help the doctor and with the nursing.

With the organization of the service and the prior preparation of the students to perform tasks that contribute to their training and assist the team, there is no loss of productivity for the service, because the students help out the team by providing other services ${ }^{18}$.

In a study carried out in the PHC setting, Traverso-Yépez and Morais ${ }^{19}$ suggest that the communication between the doctor and the patient tends to be unsatisfactory, due to the limited time that most of these professionals have available, having to juggle so many different activities, and to the use of technical language that users may find difficult to understand. 
In the discussions analysed here, there seems to be a satisfaction, among the team members, with the students' availability to listen to the patients and give them more attention.

\section{The integration of teaching, service and community} contributes to the medical training

The participants also discussed another category, which is the students' professional training. They agreed that the student should learn in a wide range of settings within the SUS, with emphasis on PHC. They highlighted in positive terms the fact that the medical course of Votuporanga places its students, from the first year of the course, in real-life PHC settings, and pointed to the transformation and empathetic and cognitive skills acquired by the students in the FHCU:

N1: [...] of course there can be no practice without theory, but this new model that the university has in Votuporanga, of bringing students from the first year into the field, contributes a lot to their growth. It's important that we provide an opportunity for the student to learn, because in the future, he will be taking care of us.

$\mathrm{N} 2:[. .$.$] being able to pass on this knowledge that everyone$ has given them a knowledge of the reality. And when they return, they know how to interact with the population and how the unit operates.

N1: We receive two groups: those who stay with the doctors every day, and those who come once a week; we see a big difference between the two groups. Those who come once a week take a little less care with the population, while those who come every day have a different attitude.

D2: Home visits enrich the practice because at the clinic, we don't think about the other needs that the patient may have; but in the [patient's] home, we find out other things, we get more involved and create bonds [...] and that make a difference afterwards, in the diagnosis.

HA5: I think we contribute a lot to their training, informing them about the reality of the place where they will work with the population [...]

We can infer that empathetic skills in interpersonal relations can be developed by students when they are presented with the patients' reality, because recognising their health needs is beneficial for the doctor-patient relationship, including helping to identify the main diagnoses.
In the FHCU, the educational process goes beyond learning the routines of the service and carrying out procedures; learning how to do things happens in response to the reality of meeting health needs, and to the problems that challenge the student to seek solutions. Reflecting on and acting critically in the actions carried out by the team, as well as the discussions and correlations from the literature on topics of relevance to the PHC, are important elements for building the new professional profile that the student seeks to acquire ${ }^{20}$.

Training with a focus on PHC favours communication and relations, because acting in this scenario requires skills in negotiation and agreement, given that this is a highly complex and diverse context that requires reflective practice on the part of professionals, to deal with situations that cannot be resolved by a biomedical logic alone ${ }^{21}$.

The reports that acknowledged that the students' activities in the PHC favour a training focused on the health-disease process, and not just on the disease itself, were interesting, as this contributes to the students' learning of preventive actions and problem-solving during the consultations of the $\mathrm{PHC}$, when the student relates to the patient, promoting an understanding of the person as a whole and enabling the diagnosis and care by the multiprofessional team:

D14: There's nothing better than working here in the practical placement as someone who observes the doctor, because it moves him away from the hospital and he will achieve the principle of current medicine, which is no longer the focus on cure, inside the hospital, but more of a preventive focus. So this is the ideal place for him to really spend time, and participate for quite some time.

DT12: Here, they have a very multiprofessional focus, they interact with many different areas [...] In addition to put into practice the theory, they will be aware of the responsibility that they have with the patient.

D14: [...] it gives them (medical students) an idea of the dayto-day problems [...] different things, that are not discussed in the technical protocols. There, you are part of a big team and each one can give his or her contribution in some form or other, in order to deal with the reality of the patient, who is more than just what they have read about in the theoretical books.

The professional practices established by the Flexnerian model, which is predominantly hospital-focused, fail to give due consideration to the understanding and action on the determinants of the health-disease process ${ }^{8}$. The relationship of 
exchange of knowledge that occurs between students, teachers, professionals and service users can contribute to forming a new profile of professionals who are committed to quality health care that meets the real needs of the population ${ }^{5}$.

The participants also talked a lot about the students' activities in the health education groups, emphasising the fact that these are important training spaces for the medical student to learn about other ways of producing health, other than patient consultations:

NA7: [...] having practical experience in (collective) health helps a lot (in the student's training), trained with different patients, different places [...] participating in groups.

These activities with the community help the students to deconstruct the idea of health education as a practice of transmission of knowledge, in which the health professional holds the knowledge and provides guidance, often out of context, to the users. Rather, it allows the students to share their knowledge gained through the patients' experiences, and to understand that this is possible in their daily medical practice ${ }^{15}$.

Another factor cited by the participants as contributing to the medical training was team work:

DT12: I think that at this site (FHCU) they have a very multidisciplinary vision, they interact with many areas. I think this is a huge responsibility for them to bear

NT4: I think that another great contribution to the training of doctors (students) is the team work [...], because each one has their own personality, each one performs a service, each area has its own reality [...] and they have an opportunity to learn about [...] various different social levels, I think it helps a lot [...] to learn to listen [...]

Each member of the team has their own knowledge, a different life history, different training. Therefore, the tendency is for us to ignore these differences and work as one might in a factory, where each one is a part of the work. But to develop team work, we need to coordinate all these characteristics without losing sight of the purpose of the work, and the specific skills and abilities of each worker ${ }^{22}$.

Teamwork requires dialog and the joint creation of care plans, defining more clearly the role of each member in relation to the patient. Hence, the students participate in team meetings and have first-hand experience of the inter-professional work that goes on.

\section{CONCLUSION}

Analysing the perceptions of health professionals of the PHC, we can conclude that in the opinions of these professionals, the integration of the student in the FHCU contributes both to the service and to the teaching and the community. The benefits include: reflective practices that improve both the quality of care and the training of the doctor; the activities developed by the students with the community, especially in health education, which promote quality of life; the complementary and reflective activities carried out by the students to support the team in resolving local problems; learning to work as part of a team, respecting the knowledge of different professionals and favouring the creation of a medical professional with a new profile, as determined in the NCG.

Some of the more difficult situations pointed out by the health professionals were: patients' embarrassment when students were present during the medical consultation, especially for those with intimate complaints requiring physical examinations where the patients were required to expose themselves more; and, at the start of the course, the student's lack of skills and ability, leading to unprofessional attitudes in the services. Another difficulty that was reported was the length of time the students remain in the FHCU, which should be longer, in order to promote bonds with the patients and the health care team.

This study suggests some changes that are needed, in the period the students remain in the FHCU settings, in order to reduce turnover and improve the bond with the team and the community. It is also important to reassess the infrastructure of the PHC, identifying new scenarios to reduce the number of students present during medical consultations.

The local community should be informed and prepared to receive the students, because it is an important part of the training for the continuity of good medical care in the municipality. The teaching institution could contribute by disseminating and raising awareness of the community about the importance of placing future professionals in real-life health care settings during their training.

Also worth noting is the lack of a multiprofessional continuing education program, since only the doctors acting as preceptors receive this type of training from the teaching institution.

We hope that the results presented here will motivate health professionals and medical schools to reflect on the PHC, both in community health focus and in the educational focus, adding value to the SUS in terms of its health care and teaching.

\section{REFERENCES}

1. Brasil. Ministério da Educação. Conselho Nacional de Educação. Câmara de Educação Superior. Resolução CNE/CES n ${ }^{\circ}$ 4, de 07 de novembro de 2001 [Internet]. 2001 
[acesso em 12 jul. 2018]. Disponível em: <http://portal. mec.gov.br/cne/arquivos/pdf/CES04.pdf>.

2. Brasil. Ministério da Educação. Conselho Nacional de Educação. Câmara de Educação Superior. Resolução CNE/ CES n ${ }^{\circ}$ 3, de 20 de junho de 2014 [Internet]. 2014 [acesso em 12 jul. 2018]. Disponível em: <http:/ / www.fmb.unesp. br/Home/Graduacao/resolucao-den-2014.pdf>.

3. UNIFEV Centro Universitário de Votuporanga. Projeto pedagógico do curso de medicina. Votuporanga: UNIFEV; 2017.

4. Pinheiro SA, Freitas MA. Ensino médico e promoção à saúde em creche comunitária. Rev Ass Med Brasil. 2001;47(4):320-4.

5. Albuquerque VS, Gomes AP, Rezende CHA, Sampaio MX, Dias OV, Lugarinho RM. A integração ensino-serviço no contexto dos processos de mudança na formação superior dos profissionais da saúde. Rev Bras Educ Méd. 2008;32(3):356-62.

6. Minayo MCS. O desafio do conhecimento: pesquisa qualitativa em saúde. São Paulo: Hucitec; 2014.

7. Bardin L. Análise de conteúdo. Lisboa: Edições 70; 2004.

8. Caldeira ES, Leite MTS, Rodrigues-Neto JF. Estudantes de medicina nos serviços de atenção primária: percepção dos profissionais. Rev Bras Educ Méd. 2011;35(4):477-85.

9. Cavalcante Filho JB. Coletivos organizados para a produção do cuidado integral: um desafio para a regulamentação profissional. Rev APS. 2009;12(2):214-20.

10. Ceccim RB, Feuerwerker LCM. O quadrilátero da formação para a área da saúde: ensino, gestão, atenção e controle social. Rev Saúde Coletiva. 2004;14(1):41-65.

11. Ferraz APCM, Belhot RV. Taxonomia de Bloom: revisão teórica e apresentação das adequações do instrumento para a definição de objetivos instrucionais. Gest Prod. 2010;17(2):421-31.

12. Brandão ERM, Rocha SV, Silva SS. Práticas de integração ensino-serviço-comunidade: reorientando a formação médica. Rev Bras Educ Méd. 2013;37(4):573-7.

13. Oliveira S, Alvarez D, Brito J. A dimensão gestionária do trabalho: aspectos da atividade de cuidado. Ciênc Saúde Coletiva. 2013;18(6):1581-9.

14. Trajman A, Assunção N, Venturi M, Tobias D, Toschi W, Brant V. A preceptoria na rede básica da Secretaria Municipal de Saúde do Rio de Janeiro: opinião dos profissionais de Saúde. Rev Bras Educ Méd. 2009;33(1):24-32.

15. Cardoso A, Souza MC. Contribuição das ações de educação em saúde para a qualidade de vida de diabéticos do bairro Ipiranga. Rev Flumin Extensão Univ. 2013;3(1/2):5-7.
16. Caetano JA, Diniz RCM, Soares E. Integração docente-assistencial sob a ótica dos profissionais. Cogitare Enferm. 2009;14(4):638-44.

17. Garg ML, Boero JF, Christiansen RG, Booher CG. Primary care teaching physicians' losses of productivity and revenue at three ambulatory-care centers. Acad Med. 1991;66(6):348-53.

18. Spencer J. Learning and teaching in the clinical environment. BMJ. 2003;326(7389):591-4.

19. Traverso-Yépez M, Morais NA. Reivindicando a subjetividade dos usuários da Rede Básica de Saúde: para uma humanização do atendimento. Cad Saúde Pública. 2004;20(1):80-8.

20. Pereira JG, Campinas LLSL, Martines WRV, Chueiri PS. Integração academia; serviço e comunidade: um relato de experiência do curso de graduação em medicina na atenção básica no município de São Paulo. Mundo Saúde. 2009;33(1):99-107.

21. Mestriner Júnior W, Mestriner SF, Bulgarelli AF, Mishima SM. O desenvolvimento de competências em atenção básica à saúde: a experiência no projeto Huka-Katu. Ciênc Saúde Coletiva. 2011;16(suppl 1):903-12.

22. Fortuna CM, Mishima SM, Matumoto S, Pereira MJB. O trabalho de equipe no programa de saúde da família: reflexões a partir de conceitos do processo grupal e de grupos operativos. Rev Latino-Am Enfermagem. 2005;13(2):262-8.

\section{AUTHORS' CONTRIBUTIONS}

FASP: participated in the conception, planning, organization, literature review, data collection, data analysis, writing and revision of the final text.

RAO: participated in data analysis and final text revision.

FAA: participated in the conception, planning, organization, bibliographical revision, data analysis, writing and revision of the final text.

\section{CONFLICTS OF INTEREST}

None of the authors declare any conflict of interest

\section{ADDRESS FOR CORRESPONDENCE}

Fernando Antonio de Almeida

Rua Joubert Wey 290, Jardim Vergueiro.

CEP 18030-070, Sorocaba-SP.

e-mail: faalmeida@pucsp.br e almeidafa@globo.com 